Original Research Paper

\title{
General Theory of Systems and Tendencies of Administration
}

\author{
Zlatko Brnjas \\ Republika Hrvatska, Karlovačka Županija, Grad Slunj, Croatia
}

Article history

Received: 2014-12-16

Revised: 2014-12-20

Accepted: 2014-12-31

Email: brnjas.zlatko@gmail.com

\begin{abstract}
In order to better understand the operation of administrative organization but also world that surrounds us we need to study the general theory of systems. Therefore, I will devote the first part of the paper to the general theory of systems. In that part of the paper I will tell what general theory of administration is and who had first introduced here into science. All systems in order to better achieve their goals in the case of competition must act according to the game theory to accomplish their goal. The second part of paper refers to the definition of the administrative system. We need Administrative systems to better understand the mode of administrative organization and administration in general and its tendencies. In order to better understand the tendencies in the paper I have given some formulas that are created by other scientists from various fields of science and some of them I've created.
\end{abstract}

Keywords: General Theory of Systems, Administration

\section{Introduction}

In today's world of increasing complexity often we don $t$ recognize some of the problems, it is therefore necessary to simplify this complexity into simple parts in order to better and more efficient get to the source of a particular problem. Complexity is especially pronounced in administrative organizations which we should consider as a separate system, which all together make up the administrative system. This is why in this study I will show the need for the application of the general theory of systems on the administrative organization and that the administrative organization should not be considered as closed systems that have a repulsive attitude toward the environment, because they think that their environment is a threat to them. Of course the environment has its negative as well as positive effects, because each organization and especially administration needs and must cooperate with other organizations and with citizens and other subjects that make up the society of a certain State.

\section{General Theory System}

When we mention the tendency of administration such as differentiation with which is immediately associate and integration, these two terms are taken from the general theory of systems (Blažević, 2010). This scientific discipline was founded by Ludwig von Bertalanffy, who believes that there are general laws of the system that can be applied to any form of system regardless of the particularities of the system. By the contribution of this scientist's general theory of systems was considered misty and half metaphysical concept.
According to the general theory of systems, atom, a local unit, plant, person, company, etc. these are all systems and units that are made up of certain parts. The theory of systems poses the forefront of system interdependencies and complexity those results from it. For some theorists it is a theory that attempts to show what are the structures and processes common to all systems, regardless of their level of complexity. The goal of general systems theory for these authors is seeking and finding what is common to all systems. In this search for the best is to be at a lower level, at the level of description and classification of statistical constructs (Cvitan, 2008). R.A. Johnson, F.E. Kast and J.E. Rosenzweig, they argue that in the area of perspectives opens up the application of cybernetic methods and computer technology. Cybernetics tends to become the general science of regulation and self regulation (Cvitan, 2008). This is on one hand good because cybernetic approach works as big machine, but on the other it creates a lot of threats due to poor flexibility to change.

A further aim of this paper is to point out the importance of tendencies of administration. Each administration has certain tendencies that can be advantages and disadvantages for a certain state. Proper application of the knowledge and how tendencies of administration work they can become a good tool for further development and improvement of not only the administration but also the entire community. I personally believe that the administrative organization and their positive work reflect the degree of development of a given society. The second approach seeks to find a particular phenomenon that is related to the multiple disciplines and with the help of an interdisciplinary approach to create a general model of this phenomenon. 
On a picturesque way of speaking C. Churchman says: "Systematic approach begins when we for the first time see the world through the eyes of others. This approach continues in the discovery that every view of the world is very limited". Studying the process of contacts, dynamism between parts of the system, rather than dealing with a static structure, particularly the feature of the methodology of general systems theory. There is no consensus or is very hard to achieve it among theorists who deal with the theory of the system, even in terms of the elements, neither what are objectives and process of interaction between the individual parts. According to some theorists, the basic parts of the system are: Individual, formal structure, informal structure, status and role in the organization and environment (Cvitan, 2008). Regardless of all disagreements theorists we can determine that each system has a certain structure. The problem of the system structure can be generally formulated as a question: how much and what kind of elements exists in the system and the linkages between them? Regardless of all disagreements between theorists we can determine that each system has a certain structure. The problem of the system structure can be generally formulated as a question: How much and what kind of elements exists in the system and what links them? First are dimensions of differentiation and more detailed dimensions of integration. Differentiation means replacing any element of the system with the other two elements or more which differ (Blažević, 2010). Integration is the establishment of at least one connection between at least two elements of the system. These two terms denote the process in the system.

When a new element of the system is created based on differentiation that part automatically we call element only for being in some way integrated into the system. Subjecting all elements of the system generally, their integration into the systemic form, we call integration. Differentiation and integration are just two aspects of the structure of the system, which means that they should not be regarded as different phenomena, for analytical reasons we use them, however, displays separately. Structural indentation of the system depends on the number and type of their element. Elements of the system we can define as the parts $f$ a system that comprises a system. Each elements of a system are connected, they are not isolated and this makes them elements of a system. In the way we can mention the degree of centralization, which depends on the opportunities offered by structure of the system to conduct one or a small number of elements influence the behavior of others and in this way to a greater or lesser extent, However other elements affecting change a state of a system as a whole. If a single element of the system does not have a decisive impact on the state of the system we are talking about a decentralized system. An important concept in systems to mention is environment.
Environment is generally referred to as a negative category, which means all phenomena that are not included in the system but are relevant for the system or their could be. We must not be guided by this idea, but one that the environment provides certain opportunities and sources of "energy" for a particular system.

Resistance of a system to specific changes depends on its resilience to adapt and to anticipate certain environmental influences. Due to contact with the environment we distinguish two types of systems: Open and closed (Bourgon, 2011). Open systems exchange information with the environment and other systems and closed with relatively little interaction with other systems and its environment. Systems must exchange information with the environment and other systems in order to avoid the entropy of the system. Each system has a limited number of elements, while the environment has a relatively unlimited number of elements. The most common of the strategies that the system has towards the environment is defensive; another type of strategy is offensive. The in defensive strategy system shuts down into himself or "escapes" while in the offensive strategy the system tries parts of the environment to its control. In these ways, each system tries to overcome the uncertainties that come from the environment. When choosing strategies each system should act according theory of games.

\section{Introduction to Administrative System}

Since everything that surrounds us can be attributed to the characteristics of a system that applies also to the administration, so we come to the system called administrative systems. The administrative system is easiest to define a set of administrative organizations that are interconnected and administrative organizations is such organization where people perform public duties (of general interest) based on the permanent division of powers and duties as their constant profession (Pusić, 2002). The administrative system must be seen as a system of a greater level of complexity or as a unit composed of parts which themselves represent a system, making them difficult to study. Science associated with administration is called Administrative science; its subject is the examination of the legality of social phenomena related to administrative organizations and activities of governance. Structures of Administrative Sciences are administrative organizations or other institutions in connection with its subject. Since the administrative organizations are complex organization, they must be part of a other scientific disciplines. Informatics in administrative organizations can study information exchange connectivity information that is of great importance for the functioning of the organization, even more recently appeared in discipline of social physics (Pentland, 2014) which seeks to build mathematical models of human interaction and bring 
order and predictability of chaotic human behavior. So the task of administrative science as every science is solving problems.

\section{Tendencies of Administration}

An administration is in its basic development Public administration and changed together with changing the state (society). It is in its sense occurs in Europe during the 17th and 18th century (the time of enlightened absolutism). From that time up today and social development in countries marked by the regularities i.e. Tendencies. The tendency is defined as a sequence of forms of development in which the more immediate forms are similar to the current layout appearance from appearances more distant in time. It is important to distinguish between statistical trends from tendencies, tendencies express such changes that cannot be quantitatively expressed, a statistical trend has only one direction of movement, no reversible development. The tendency operates within one community, in a defined space and time. In the long-term perspective tendencies are general and go over the boundaries of a community and it is in short intervals are very difficult to see. Since the world that surrounds us is chaotic and not predictable, there are phenomena that cannot be or are very difficult to identify trends such as wars, earthquakes, etc., which we call the intervening factors/accompanying values. In the development of administration are distinguish five tendencies. These tendencies are: The tendency of growing administrative organizations, the tendency toward differentiation of administrative organizations, the tendency toward professionalization of administration, the tendency toward the limitation of force in the administration and the trend towards computerization of administration.

\section{The Tendency of Growing Administrative Organizations}

We are witnessing the continual growth of the various organizations over the years, due to rising tendencies of administration. Increased requirements for social regulation triggers the required increase in the administrative apparatus. The concept of growing administrative organizations first warned a economist by the name of Adolf Wagner that was particular expressed in last fifty years. Administrations, often grows over the production possibilities of a particular community. The growing of administrative organizations can be apsolutivan or relative (Blažević, 2010). The absolute growth means that the development of administrative systems of each country include more people and more organizations and relative means that the administrative system of a country developing engage an increasing percentage of manpower and material resources. One of the main causes of the growth of a administration is the development of social productive potential. Next reason of growth is urbanization, which means the process of increasing urban population in the total population. Using population, $N(t)$, as a measure of the size of the city at a particular time we come to the formula:

$Y(t)=Y 0 N(t)^{\beta}$

$\mathrm{Y}$ indicates the material resources like energy or infrastructure or measure of social activities such as wealth, patents and pollution. $\mathrm{Y}_{\mathrm{o}}$ is a normalizing constant, the exponent $\beta$ reflects the general dynamic rules that operate across urban systems (West, 2007). Next cause of growth of administrative organizations is the process of globalization, which is the process of spreading all good and the bad things. Next cause of growth of administration can be found in the development of internal administrative functions such as personal services, register, etc. The next factor of growth is Parkinson's Law, created from scientists C. Northcote Parkinson which consists from two factors. The first states that every employee is trying to increase the number of his subordinate employees but never rival and opponent, the other says that servants create jobs to one another so that all are too busy. The increase in administration can have negative or positive effects if it grows according to need of population it has positive effect. Parkinson low is made by the formula where his law can be expressed in mathematical terms:

$$
x=\frac{k^{m}+L}{n}
$$

Where:

$\mathrm{x}=$ A number of new employees each year

$\mathrm{k}=$ Number of employees who seek to improve the recruitment of new subordinates

$\mathrm{m}=$ Number of working hours per employee, required for the carrying out the memorandum used in the inner office traffic

$\mathrm{L}=$ The difference between the old setting and retirement

$\mathrm{n}=$ Number administrative unit that the office staff really processed

\section{The Tendency Towards Professionalization of Administration}

Over time activities of administrative organizations have become more permanent and of a permanent character, unlike in the pre-capitalist era where there were honorary governance, where people have not received any compensation for their work and they are $t$ educated for the work in administration. In professionalization of administration we distinguish the component of stasis/stabilization of positions in administrative organizations as stability of tasks and 
stability of their personal position holders i.e. permanent jobs that must be carried out and component transition from novice to professional officers who were educated for this profession. The above tendency is manifested in the form of increasing the number officers. According to this we distinguish four systems.

The first is when the officials held at the court of the ruler (chamberlains, squires) and have supported their ruler from the warehouse. Another form of payment we found in Egypt and China and it is a payment in the nature. An employee is given food or clothing taken away from sellers in taxes. The third form of payment is the assignment of revenue sources with two main types: The allocation of land and allocation of income and fourth form of payment in cash, which are dominant with the transition from barter to the monetary economy. Today people who work in administrations are educated for the job.

\section{Tendency Toward the Limitation of Force in the Administration}

Coercion is applied in administrative organizations inside the administrative organization and toward the members of community. Limitation of force in the administration and toward members of the community is the result of democratization and civilization or citizenship. Coercion was primarily emphasized at the beginning of the administrative development. In terms of natural economy the State didn't have economic mechanisms for the distribution of the workforce, so that government had to use coercion in order to motivate people to perform certain enterprise (construction of embankments, pyramids etc.).

The degree of coercion towards the community of an organization can be calculated using the following formula:

$P=\frac{X O+X P}{Y b}$

Where:

$\mathrm{XO}=$ The number of warnings

$\mathrm{XP}=$ Represents the number of resorting to coercion in order to fulfill certain obligations

$\mathrm{Yb}=$ Represents the number of cases resolved without coercion

The degree of coercion within an organization can be calculated in the following way:

$P 0=\frac{N l+N t}{n}$

Where:

$\mathrm{Nl}=$ Represents the number of light violation of official duty
$\mathrm{Nt}=$ The number of serious violations of procedures and $\mathrm{n}$ is the number of workers

The Tendency Towards the Computerization of Administration

We have witnessed the rapid growth of computerization in all aspects of our society and there is no doubt that our time is a time of a computer and virtually invisible world. A few years ago we could not imagine to study over the Internet, but today it is equally represented as "normal" studying thanks to organizations such as EDX. Therefore, we can rightfully speak about the information-communication-technology revolution that marked the end of the 20th and beginning of the $21 \mathrm{st}$ century (Blažević, 2010). There are two types of society, such as information and industrial society. Administration tends to increasing use of computers in order to be more efficient and as quickly performing everyday tasks. Therefore, there is a problem of the increasing demand of workers in the field of computer science in the administration who need to maintain all systems that are necessary for the functioning of the administrative system.

\section{The Tendency of Differentiation of a Administrative Organizations}

Like every system, administrative system shows tendency toward division of labor, we distinguish two types of differentiation: Horizontal and vertical (Blažević, 2010). Applying horizontal differentiation we create new parallel parts of the administrative system on the same geographical extent that differ in type of work.

Simply we can imagine like this: Person A perform a group of tasks $\mathrm{p}_{1}, \mathrm{p}_{2}, \mathrm{p}_{3}, \mathrm{p}_{4}$ where to do the job $\mathrm{p}_{4}$ need twice as much time than to do all other jobs. So the job $\mathrm{p}_{4}$ is allocated in the a separate job. Vertical differentiation means increasing the complexity of the administrative system from its top to bottom. It consists in the formation of territorial units that perform the same or similar tasks, but at the other territory or other users. For a organization more significance is horizontal differentiation because according to here it can be easy seen the excess and shortage of workers. Horizontal differentiation can be represented by the formula:

$$
H d=P 1(t)+P 2(t)+P 3(t)+P 4(t)+\ldots P n(t)
$$

where, Hd denotes horizontal decentralization, P1...n denotes work and mark $\mathrm{t}$ the time required to perform the job.

\section{Conclusion}

Through this paper I have tried to point out and also draw attention to the need for systematic study of 
administration. General systems theory gives us a framework of what the system actually and what makes it a system. Since each system is specific, especially administrative system, which we have to look as the systems of more complexity and we must be familiar with the facts in favor and against the system so that we could work perfectly. Administrative systems are often looked as a closed system that is wrong. We should see him as a system that is dependent on all components of society. Especially in this age of uncertainty and instability. It is extremely important in the study of administrative systems and institutions, good knowledge of tendencies of administration, because they can destroy and build administration

\section{Acknowledgment}

My special thanks to the my current professor Blazević, also thanks go to $\mathrm{C}$. Northcote Parkinson and to professor Pusić, Geoffrey B. West for the equation of population.

\section{Funding Information}

Founder of this paper is Zlatko Brnjas, secretary of elementary school Donji Lapac and current graduate student majoring in public administration.

\section{Author Contribution}

Zlatko Brnjas is the only author of this paper and everything related to the paper is associated with him.

\section{Ethics}

All the sources used in this work are listed.

\section{References}

Blažević, R., 2010. Upravna Znanost, Zagreb. Društveno Veleučilište.

Bourgon, J., 2011. A new synthasis of public administration. School of Public Studies, Canada.

Cvitan, O., 2008. Upravna ogranizacija. Šibenik.

Pentland, A., 2014. Social Physics: How Good Ideas Spread-The Lessons from a New Science. The Penguin Press, New York, ISBN-10: 1101625570 , pp: 320.

Pusić, E., 2002a. Nauka o Upravi, 12. Izdanje, Školska Knjiga, Zagreb.

West, G.B., 2007. Growth, innovation, scaling and the pace of life in cities. Pnas, 14: 7301-7306. 